\title{
Progressive Visual Loss from Roth Spots in a Patient with Infective Endocarditis
}

\section{Meheroz H Rabadi* and Paul M. Munden}

Department of Neurology, Veterans Affairs Medical Center, Oklahoma University, USA

\begin{abstract}
Infective Endocarditis (IE) implies infection of the endocardial surface of the heart from the presence of microorganisms in the lesion. The variability in clinical presentation, heterogeneous patient population and microbiologic organisms makes the IE diagnosis challenging for clinicians.
\end{abstract}

Keywords: Endocarditis Roth spots; Multiple Emboli; Stroke

\section{Case Presentation}

A 60-year-old edentulous man with past medical history of hyperlipidemia, current smoker, and depression presented to the eye department with a 4-week history of progressive blurred vision. As per patient he saw a "white sheet" in front of his eyes worse in the right eye constantly. After his eye evaluation he was referred to the neurology clinic as he complained of having difficulty finding words to express him-self. He did report of having lost $10 \mathrm{lbs}(4.5 \mathrm{~kg})$ in weight during this period but no other complains such as fever, fatigue, sweating, chest pain, shortness of breath or any other neurological complains. There was no history of substance abuse including history of intravenous drug use.

\section{Assessment}

On general evaluation his Body Mass Index (BMI) was 26, had no clubbing or other skin manifestations such as splinter hemorrhages, petechiae (Osler nodes and Janeway lesions). He had no cardiac murmurs or extra heart sounds on auscultation. On abdominal examination there was no visceromegaly specially splenomegaly. His neurological examinations including his language were normal. His eye examination the fundus showed multiple, bilateral, white-centered retinal hemorrhages which were "Roth spots" (Figure 1).

\section{Diagnosis}

On initial work-up his hemoglobin was $9.5 \mathrm{~g} / \mathrm{dL}$, Mean Corpuscular

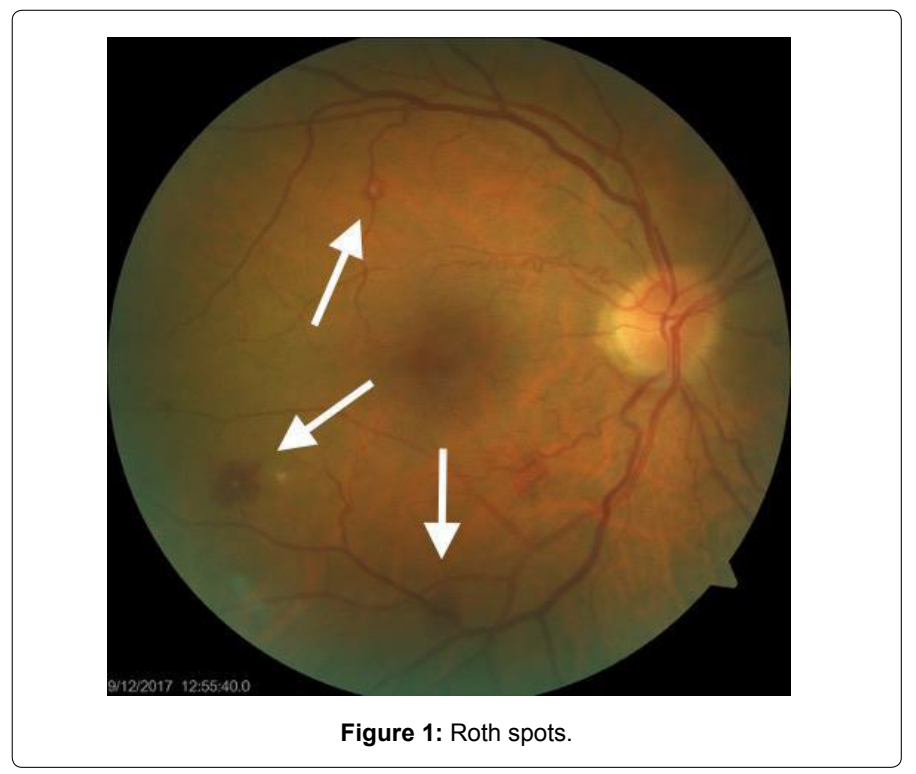

Volume $72.8 \mathrm{fl}$ with white cell count 11.7x 109/L. His sedimentation rate was $105 \mathrm{~mm} / \mathrm{h}$, and a C-reactive protein was $198 \mathrm{mg} / \mathrm{L}$. His blood urea nitrogen was $9 \mathrm{mg} / \mathrm{dL}$ with a creatinine of $0.9 \mathrm{mg} / \mathrm{dl}$, normal glomerular filtration rate greater than $60 \mathrm{~mL} / \mathrm{min} / \mathrm{L}$, but urine analysis showed frank hematuria (4 Red Blood Cells/High Power Field). Head Magnetic Resonance Imaging (HMRI) demonstrated an acute infarct in the left frontal lobe on Diffusion Weighted Image (DWI) confirmed by Apparent Diffusion Coefficient (ADC) (Figures 2a and 2b). Abdominal Computerized Tomography (CT) scan showed presence of splenic and bilateral renal infarcts (Figure 2c). Blood cultures grew Streptococcus oralis. Trans-thoracic echocardiogram showed mitral regurgitation with

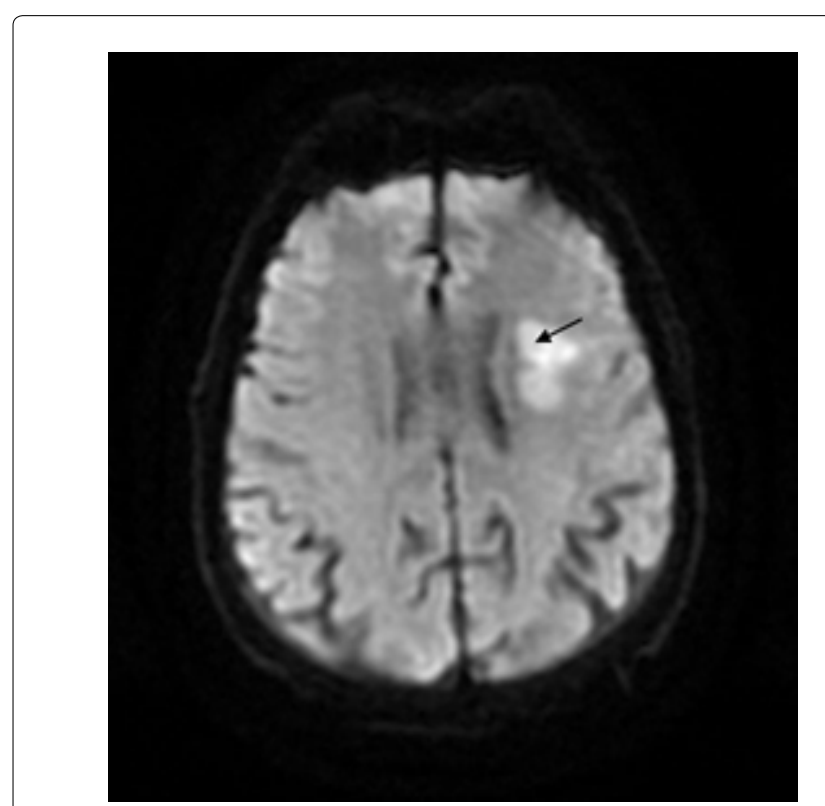

Figure 2a: Cerebral infarction (stroke) on Diffusion Weighted Image (DWI).

*Corresponding author: Meheroz $\mathrm{H}$ Rabadi, MD, MRCPI, FAAN, FANA, Clinical Professor of Neurology at the OUHSC, Veterans Affairs Medical Center at Oklahoma University, 921 NE 13 ${ }^{\text {th }}$ Street, Oklahoma City, OK 73104, USA, Tel: 405-456-5298; Fax: 405-456-1504; E-mail: rabadimh@gmail.com

Received October 08, 2018; Accepted October 31, 2018; Published November 07, 2018

Citation: Rabadi MH, Munden PM (2018) Progressive Visual Loss from Roth Spots in a Patient with Infective Endocarditis. Int J Neurorehabilitation 5: 333. doi: 10.4172/2376-0281.1000333

Copyright: (c) 2018 Rabadi MH, et al. This is an open-access article distributed under the terms of the Creative Commons Attribution License, which permits unrestricted use, distribution, and reproduction in any medium, provided the original author and source are credited. 


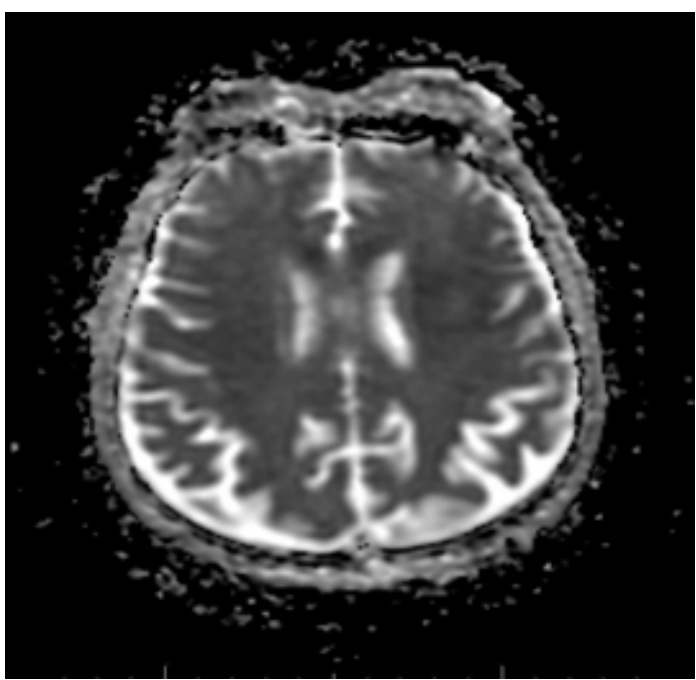

Figure 2b: Cerebral infarction (stroke) on Apparent Diffusion Coefficient (ADC)

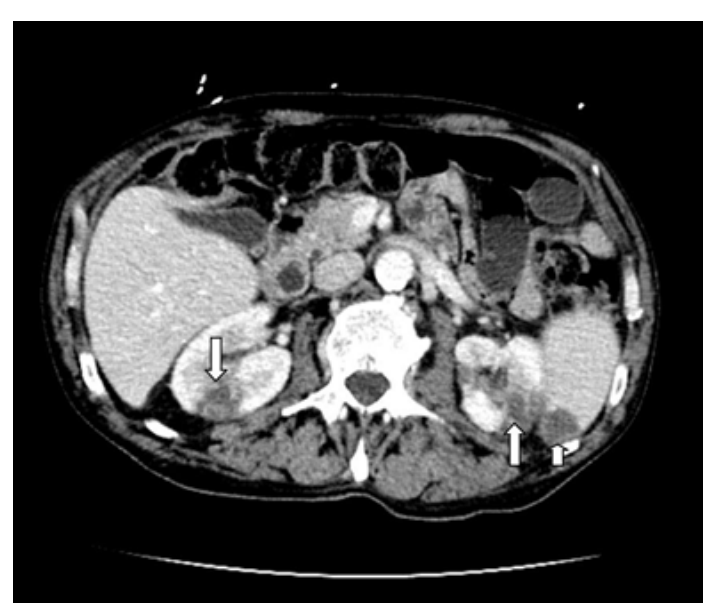

Figure 2c: Renal and splenic infracts.

medium sized mobile mitral valve vegetation on the left ventricular aspect of the anterior leaflet, the source of his generalized embolization (Figure 3).

\section{Management}

He was initially treated empirically with intravenous (IV) vancomycin and ceftriaxone. On receipt of culture and sensitivity report he was changed to IV ceftriaxone daily. He was discharged home a week later to continue his parenteral ceftriaxone daily for 9 weeks. When last seen in the clinic 3 months later he had no new neurological complains, felt clinically improved with no growth on three separate blood cultures. He was also advised about the vital importance of dental hygiene and need for antibiotic prophylaxis when undergoing dental procedure/care. He is now awaiting mitral valve replacement surgery.

\section{Discussion and Conclusion}

This case of Infective Endocarditis (IE) according to the Duke criteria [1] is unique in several ways: First, he had no known history of valvular heart disease; second, was edentulous with no recent history of dental procedure [2]; third, his presenting symptom was mainly blurred

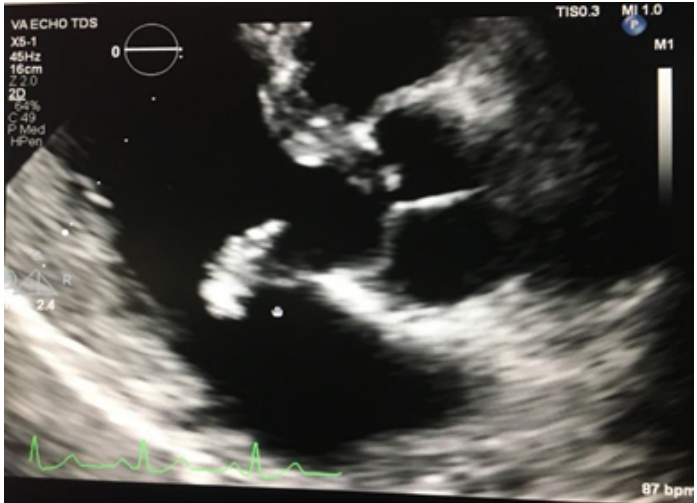

Figure 3: Vegetation on the mitral valve (mobile).

vision which affected his ability to drive and work; and finally, the organism responsible was Streptococcal viridans. IE is now a day more common in men than women [3], who are older (greater than 50 years of age) [4] due to rise in the frequency of degenerative valvular heart disease [5]. Staphylococcus aureus is the leading cause of bacteremia and IE. Mitral valve is the most commonly affected valve in $86 \%$ cases, followed by aortic $55 \%$, tricuspid in $19.6 \%$, and pulmonic $1.1 \%$ cases. This is due to degree of the mechanical stress exerted by the valve [6]. Splenic septic emboli are common during IE [7]. The risk of stroke is increased in patients with mitral than aortic valve involvement [8], especially if they are of a larger size $(>1 \mathrm{~cm})$ and mobile vegetation as in this patient [9]. Trans-esophageal echocardiogram is more sensitive than conventional trans-thoracic echocardiogram (95\% vs. $60-65 \%)$ [10]. Parenteral antibiotic therapy is preferred over oral antibiotic therapy, antibiotic treatment should be based on microbiologic etiological agent [11], and combination antibiotic therapy is advised in streptococcal infections [12]. Ceftriaxone was chosen as it has a high cure rate of $98 \%$. Roth spots are named after Moritz Roth a pathologist at the University of Basel in 1872 [13]. They are characterized by retinal hemorrhages with a white center. The white center of the Roth spot corresponds to a platelet-fibrin thrombus at the site of the retinal capillaries rupture $[14,15]$. They are usually caused by immune complex mediated vasculitis. They can appear and disappear within hours. They occur in a wide variety of systemic conditions such as anemia, anoxia, leukemias, carbon monoxide poisoning, prolong intubation during anesthesia, human immunodeficiency virus retinopathies, diabetic and hypertensive retinopathies, pre-eclampsia and shaken baby syndrome; however, they are considered pathognomonic for Bacterial Endocarditis (BE). Thus, Roth spot is a morphological manifestation of retinal capillary rupture and a careful systemic evaluation is needed to elucidate the underlying cause. There is no specific treatment for Roth spot other than treat the underlying cause.

\section{References}

1. Durack DT, Lukes AS, Bright DK (1994) New criteria for diagnosis of infective endocarditis: Utilization of specific echocardiographic findings. Duke Endocarditis Service. Am J Med 96: 200-209.

2. Cabell CH, Jollis JG, Peterson GE, Corey GR, Anderson DJ, et al. (2002) Changing patient characteristics and the effect on mortality in endocarditis. Arch Intern Med 162: 90-94.

3. Harris SL (1992) Definitions and demographic characteristics In: Kaye D ed Infective Endocarditis. New York Raven Press, US.

4. Lien EA, Solberg CO, Kalager T (1998) Infective endocarditis 1973-1984 at the Bergen University Hospital: Clinical feature, treatment and prognosis. Scand J Infect Dis 20: 239-246. 
Citation: Rabadi MH, Munden PM (2018) Progressive Visual Loss from Roth Spots in a Patient with Infective Endocarditis. Int J Neurorehabilitation 5: 333. doi: 10.4172/2376-0281.1000333

5. McKinsey DS, Ratts TE, Bisno AL (1987) Underlying cardiac lesions in adults with infective endocarditis. The changing spectrum. Am J Med 82: 681-688.

6. Lepeschkin E (1952) On the relation between the site of valvular involvement in endocarditis and the blood pressure resting on the valve. Am J Med Sci 224 318-319.

7. Ting W, Silverman NA, Arzouman DA, Levitsky S (1990) Splenic septic embol in endocarditis. Circulation 82: 105-109

8. Heiro M, Nikoskelainen J, Engblom E, Kotilainen E, Marttila R, et al. (2000) Neurologic manifestations of infective endocarditis: A 17-year experience in a teaching hospital in Finland. Arch Intern Med 160: 2781-2787.

9. Sanfilippo AJ, Picard MH, Newell JB, Rosas E, Davidoff R, et al. (1991) Echocardiographic assessment of patients with infectious endocarditis: Prediction of risk for complications. J Am Coll Cardiol 18: 1191-1199.

10. Erbel R, Rohmann S, Drexler M, Mohr-Kahaly S, Gerharz CD, et al. (1998) Improved diagnostic value of echocardiography in patients with infective endocarditis by transoesophageal approach: A prospective study. Eur Heart J 9: 43-53.
11. Baddour LM, Wilson WR, Bayer AS, Fowler VG Jr, Tleyjeh IM, et al. (2015) Infective endocarditis in adults: Diagnosis, antimicrobial therapy and management of complications: A scientific statement for healthcare professionals from the American Heart Association. Circulation 132: 14351486.

12. Andrews MM, von Reyn CF (2001) Patient selection criteria and management guidelines for outpatient parenteral antibiotic therapy for native valve infective endocarditis. Clin Infect 33: 203-209.

13. Roth M (1872) Retinal manifestations of wound fever. Deutsch A Chir 1: 471 484

14. Von Barsewisch B (1979) Perinatal retinal hemorrhages. New York: SpringerVerlag, US. Pp: 51-52.

15. Duane TD, Osher RH, Green WR (1980) White centered hemorrhages: Thei significance. Ophthalmology 87: 66-69. 